\title{
Incipient motion of sediment in rectangular open-channel flow with a submerged rigid vegetation zone
}

\author{
W. Xue, S. Wu, X. Wu, J. Zhou \& J. Dai \\ State Key Laboratory of Hydrology-Water Resources and Hydraulic Engineering, Nanjing Hydraulic \\ Research Institute, Nanjing, People's Republic of China
}

\begin{abstract}
An experimental statistical method is here developed to investigate the incipient motion in open channel blocked with an artificial submerged rigid vegetation patch. We focus on the effects of vegetation elements on the incipient motion of sediment and the scour around the vegetation elements. The incipient motion of sediment is divided into three processes, the static, the partially motion, and the entirely motion, and the third process is defined as the criterion for incipient motion of sediment. Based on the experimental results, a semi-empirical equation for the sediment incipient velocity in the presence of submerged vegetation is derived, which is observed to be smaller than that without vegetation. A strong linear relationship between the average depth of the scour holes around the vegetation elements and the flow velocity is found.
\end{abstract}

\section{INTRODUCTION}

The importance of aquatic and riparian plants to the status of aquatic ecosystems and fluvial environments has been widely studied.

Many experimental studies on flow through submerged and emerged vegetation blocked on a fixedbed had focused on vegetation effects in the benthic riparian environment. Dunn et al. (1996) and Nepf \& Vivoni (2000) observed that the mean stream-wise velocity profile within a submerged or emergent vegetated layer no longer follows the universal logarithmic law. Ghisalberti \& Nepf $(2002,2004)$ found that flow through submerged vegetation exhibited characteristics of a mixing layer, including inflection of the velocity profile, increased correlation between longitudinal and vertical turbulent fluctuations, and momentum transfer driven by roller vortices generated by shear (Kelvin-Helmholtz) instability. White $\&$ Nepf (2008) conducted experiments in a partially vegetated shallow channel and developed a method for predicting the distribution of velocity and shear stress, and they found that the velocity profile exhibited a distinct two-layer structure, consisting of a rapidly varying shear layer across the vegetation interface and a more stable boundary layer in the main channel. However, these studies just investigated the vegetation effect on the flow through the vegetation zone, but did not consider the factor of the sediment.

In recent years, researchers (Tal \& Paola 2010, Zong \& Nepf 2010, Choi \& Kang 2004, Lopez \& Garcia 1998) had also examined suspended sediment with changes in the flow turbulence within or around vegetation zone. The deposition of suspended sediment was also observed with in vegetation and between an open channel and a vegetation zone (Zong $\&$ Nepf 2010, 2011). The settling of fine sediment with vegetation in different configurations was studied by Elliott (2000) and found that some suspended sediment was deposited on the surfaces of plants, meaning that the surfaces of aquatic vegetation intercept settling sediment and thereby promote sediment deposition. On the other hand, a decrease in suspended sediment had been discovered around the leading edges of vegetation patches (Zong \& Nepf 2011, Follett \& Nepf 2012).

Further studies on bed load with vegetation had been conducted based on earlier information about flow with vegetation. Specht (2002) conducted experiments to study the influence of vegetation on the geometry of sand dunes and found that the dunes became steeper and more regular in the flow direction with vegetation. Local scour had also been found around the leading edge of a vegetation patch due to enhanced local erosion, which was caused by an increase in turbulence like horseshoe vortices and stem wakes (Zong \& Nepf 2011, Follett \& Nepf 2012). The shear stress in river beds and the incipient motion in flows with non-submerged rigid vegetation were analyzed by Watanabe et al. (2002) and the experimental results showed that the incipient motion shear stress of bed load was much larger with vegetation than without vegetation. And this shear stress was found to be influenced by the vegetation density, the ratio of sediment particle size to vegetation diameter, and the ratio of the number of vegetation el- 
ements along a cross-sectional distribution to element diameter. Kothyari et al. (2009) conducted experiments to derive a semi-empirical equation for the bed load transport rate under the influence of vegetation parameters and show that the grain shear stress rather than the apparent shear stress was observed to better describe the variations in the rate of sediment transport by vegetated flows.

Up to now, previous studies described above have shown that the vegetation in the open channel has a significantly influence on the characteristics of bed load movement. However, many researches (Kothyari et al. 2009, Neary et al. 2011) always neglected the incipient motion of sediment with vegetation which was always treated the same as that without vegetation in the derivation of semi-empirical equations for bed load transport rate. So there are little studies in the literature on the incipient motion of sediment in open channel with submerged vegetation.

In this paper, we describe a study of the flow, scour, and transport processes through regular arrays of circular vegetation elements, which are regarded as idealized rigid submerged vegetation. The incipient motion of sediment with submerged vegetation, and the difference between incipient motion of sediment with vegetation and that without vegetation, are investigated. And the relationship between the average depth of the scour holes around the vegetation elements and the spatially averaged velocity for different vegetation density is also analyzed.

\section{THEORETICAL STUDY}

The bed load interacting with the flow moves under the influences of two types of force: one type encouraging motion and including the lift force $F_{L}$ and the drag force $F_{D}$; the second type discouraging motion and including the buoyed weight of sediment $W$ (Shields 1936) and cohesive force between the sediment particles $N$ (Tang 1963).

$F_{D}=C_{D} a_{1} d^{2} u^{2} / 2 g$

$F_{L}=C_{L} a_{2} d^{2} u^{2} / 2 g$

$W=a_{3}\left(\gamma_{\mathrm{s}}-\gamma\right) d^{3}$

$N=a_{4} \gamma d^{2}\left(d_{1} / d\right)^{\mathrm{s}}\left(h_{a}+h\right)$

where $d$ is the sediment size; $\gamma$ and $k_{s}$ are the volume weight of water and sediment, respectively; $C_{D}$ and $C_{L}$ are drag coefficients for $F_{D}$ and $F_{L}$, respectively; $a_{1}$ and $a_{2}$ are longitudinal and vertical area coefficients of the sediment; $a_{3}$ is the volume coefficient of the sediment; $a_{4}$ is the void coefficient of sediment; $d_{1}$ is the sediment relative size; $h$ is the water depth and $h_{a}$ is the height of water column corresponding to the atmospheric pressure.
When sediment experiences incipient motion, the momentum balance in the stream-wise direction yields the following expressions:

$K_{1} d F_{D}+K_{2} d F_{L}=K_{3} d W+K_{4} d N$

where $K_{1} d, K_{2} d, K_{3} d$ and $K_{4} d$ are the arm of force correspond to the $F_{D}, F_{L}, W$ and $N$, respectively.

Substituting Eqs. (1)-(4) into Eq. (5) yields the following expression:

$$
\begin{aligned}
& u_{b c}=\left(\frac{2 K_{3} a_{3}}{K_{1} C_{D} a_{1}+K_{2} C_{L} a_{2}}\right)^{1 / 2}\left[\frac{\rho_{s}-\rho}{\rho} g d\right. \\
& \left.+\frac{K_{4} a_{4}}{K_{3} a_{3}}\left(\frac{d_{1}}{d}\right)^{s} g\left(h_{a}+h\right)\right]^{1 / 2}
\end{aligned}
$$

where $u_{b}$ is the near-bed velocity and the subscript $c$ denotes incipient motion.

Because the spatial distribution of velocity with vegetation is not uniform but rather varies depending on the flow depth and density of vegetation (Yan et al. 2006), the near-bed velocity of sediment varies by location in flows with vegetation. The near-bed velocity is difficult to determine experimentally, so in this paper, the spatially averaged velocity for sediment incipient motion $U_{p c}$ under the interface of the water-vegetation $(z=H)$ is used as a substitute for $u_{b c}$, and we propose the following:

$U_{p c}=\frac{1}{n} \sum_{i=1}^{n} u_{i}=f\left(\frac{h}{D}, \frac{d}{D}, \alpha\right) u_{b c}$

$U_{p c}=f\left(\frac{h}{D}, \frac{d}{D}, \alpha\right)\left(\frac{2 K_{3} a_{3}}{K_{1} C_{D} a_{1}+K_{2} C_{L} a_{2}}\right)^{1 / 2}$

$\left[\frac{\rho_{s}-\rho}{\rho} g d+\frac{K_{4} a_{4}}{K_{3} a_{3}}\left(\frac{d_{1}}{d}\right)^{s} g\left(h_{a}+h\right)\right]^{1 / 2}$

where the subscript $i=$ locations for measuring velocity; $n=$ the total number of locations; $u_{i}=$ the vertical-averaged velocity of the $i$ th location under the interface of the water-vegetation $(z=H)$, as shown in Fig. $1 ; D=$ vegetation element diameter, and $\alpha=$ density of vegetation.

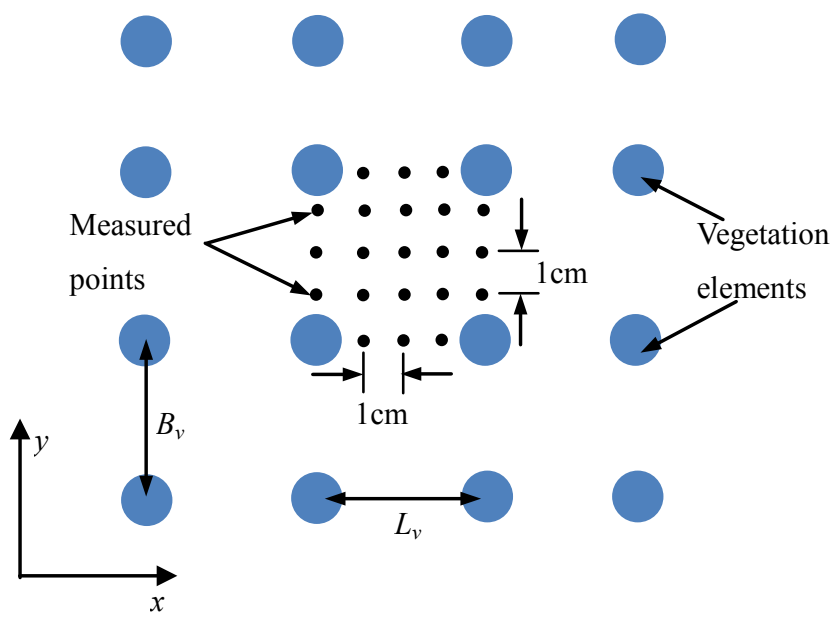

Figure 1. The measured points in the vegetation zone 


\section{EXPERIMENTAL METHODS}

\subsection{Experimental setup}

The Laboratory experiments were conducted in Hydraulics and Fluid Mechanics Laboratory at Nanjing Hydraulic Research Institute. The experimental setup is shown in Fig. 2. The experimental tilting rectangular flume was $12 \mathrm{~m}$ long, $0.4 \mathrm{~m}$ wide, and $0.4 \mathrm{~m}$ deep, with glass side walls and bottom. The slope of the flume is adjustable to achieve different uniform flows. Flow discharges were taken by a rectangle measuring weir. Velocity measurements were made using a three-dimensional acoustic Doppler velocimeter (ADV) at a sampling frequency of $50 \mathrm{~Hz}$ (Fig 2(b)). To simulate vegetation accurately in a geometric configuration, rigid vegetation elements of circular cross-sectional shape were positioned in the middle of the flume (Nepf \& Vivoni 2000, Ghisalberti \& Nepf 2004). The vegetation zone was $4 \mathrm{~m}$ long (as shown in Fig. 2) and the resulting vegetation density varied from 0.017 to 0.050 (see Table 1). $L_{v}$ and $B_{v}$ represent the neighboring vegetation elements spacing in spanwise and streamwise directions, respectively, as shown in Fig. 1. Each vegetation element had a diameter $D=8 \mathrm{~mm}$. The tests were performed using two sizes of quartz sand with the density of the sediment $\rho_{s}=2650 \mathrm{~kg} / \mathrm{m}^{3}$. The two sediment beds were uniform in gradation with a geometric standard deviation of sediment sizes of less than 1.1. Table 1 summarizes part of the data collected from the execution of 51 experiments.

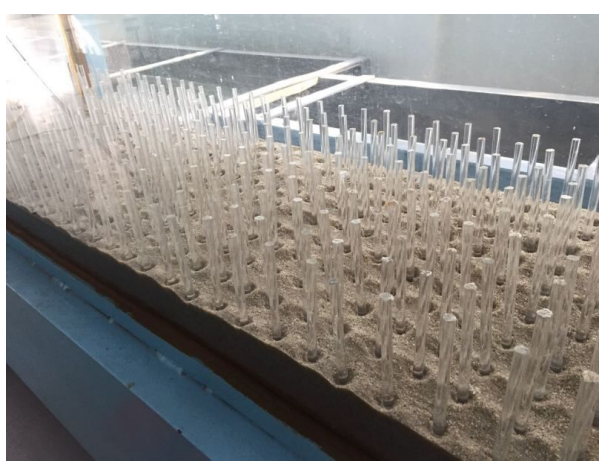

(a) Sand bed with artificial rigid vegetation elements

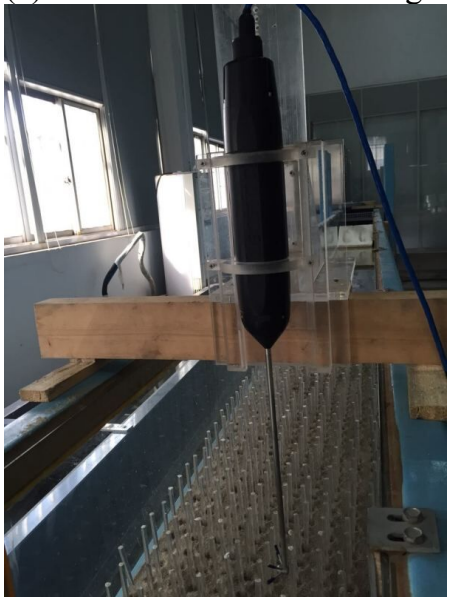

(b) Acoustic Doppler velocimeter

Figure 2. Experimental setup of rectangular flume and sand bed with rigid vegetation zone

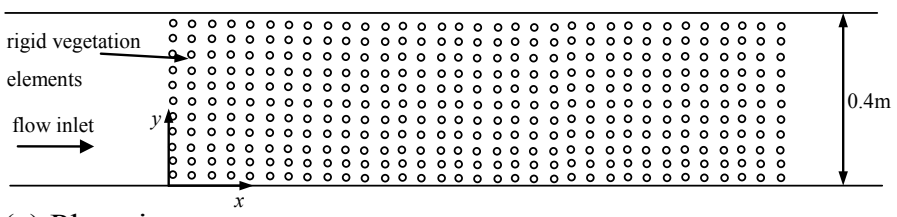

(a) Plan view

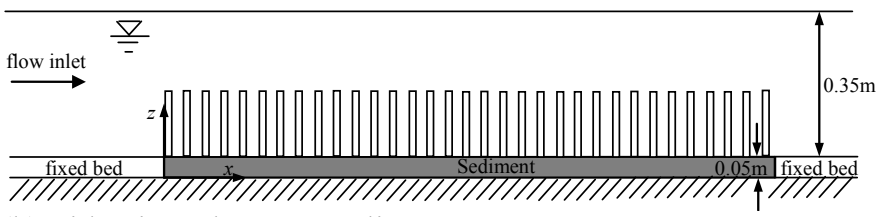

(b) Side view along centerline

Figure 3. Sketch of artificial rigid vegetation zone

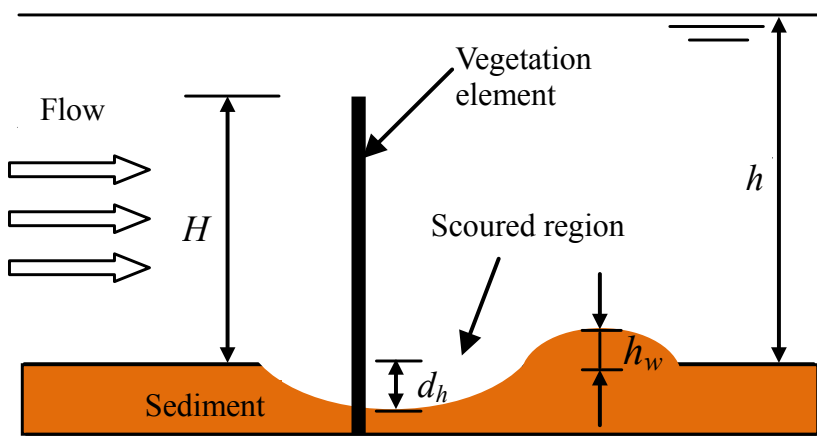

Figure 4. Scour hole parameters around one vegetation element

As illustrated in Fig. 3, the $x$-axis is in the main flow direction, the $y$-axis is transverse to the flow direction, and the $z$-axis is vertical. The origin of the coordinate system is set at the center of the upstream end of the vegetation zone. Fig. 4 shows the scour hole parameters around one vegetation element, the $d_{h}$ and the $h_{w}$ are the scour depth and the deposition height, respectively, after the flow and scour reach equilibrium. 


\begin{tabular}{|c|c|c|c|c|c|c|c|c|c|}
\hline Case & $\begin{array}{l}\text { Sand di- } \\
\text { ameter } d \\
\mathrm{~mm}\end{array}$ & $\begin{array}{l}L_{v} \\
\mathrm{~cm}\end{array}$ & $\begin{array}{l}B_{v} \\
\mathrm{~cm}\end{array}$ & $\begin{array}{l}\text { Vegetation } \\
\text { density } \alpha \\
1 / \mathrm{cm}\end{array}$ & $\begin{array}{l}\text { Flow } \\
\text { depth } h \\
\mathrm{~cm}\end{array}$ & $\begin{array}{l}\text { Vegetation ele- } \\
\text { ment diameter } D \\
\mathrm{~cm}\end{array}$ & $\begin{array}{l}\text { Vegetation ele- } \\
\text { ment length } H \\
\mathrm{~cm}\end{array}$ & $\begin{array}{l}U_{p c} \\
\mathrm{~m} / \mathrm{s}\end{array}$ & $\begin{array}{l}\text { Scour } \\
\text { depth } d_{h} \\
\mathrm{~cm}\end{array}$ \\
\hline Case 1.1 & 0.5 & NA & NA & 0 & 12.2 & NA & NA & 0.2595 & NA \\
\hline Case 1.2 & 0.5 & NA & NA & 0 & 17.0 & NA & NA & 0.2686 & NA \\
\hline Case 1.3 & 1.0 & NA & NA & 0 & 12.0 & NA & NA & 0.3402 & NA \\
\hline Case 1.4 & 1.0 & NA & NA & 0 & 15.0 & NA & NA & 0.3390 & NA \\
\hline Case 2.1 & 0.5 & 4 & 4 & 0.050 & 12.2 & 0.8 & 10 & 0.1525 & 0.80 \\
\hline Case 2.2 & 0.5 & 4 & 4 & 0.050 & 17.0 & 0.8 & 10 & 0.1526 & 0.82 \\
\hline Case 2.3 & 0.5 & 4 & 4 & 0.050 & 19.7 & 0.8 & 10 & 0.1539 & 0.85 \\
\hline Case 2.4 & 0.5 & 6 & 4 & 0.033 & 12.0 & 0.8 & 10 & 0.1549 & 0.75 \\
\hline Case 2.5 & 0.5 & 6 & 4 & 0.033 & 17.0 & 0.8 & 10 & 0.1550 & 0.76 \\
\hline Case 2.6 & 0.5 & 6 & 4 & 0.033 & 20.0 & 0.8 & 10 & 0.1550 & 0.78 \\
\hline Case 2.7 & 0.5 & 4 & 6 & 0.033 & 12.4 & 0.8 & 10 & 0.1586 & 0.74 \\
\hline Case 2.8 & 0.5 & 4 & 6 & 0.033 & 17.5 & 0.8 & 10 & 0.1589 & 0.72 \\
\hline Case 2.9 & 0.5 & 4 & 6 & 0.033 & 20.1 & 0.8 & 10 & 0.1590 & 0.73 \\
\hline Case 2.10 & 0.5 & 6 & 6 & 0.022 & 12.5 & 0.8 & 10 & 0.1622 & 0.70 \\
\hline Case 2.11 & 0.5 & 6 & 6 & 0.022 & 20.0 & 0.8 & 10 & 0.1632 & 0.69 \\
\hline Case 2.12 & 0.5 & 8 & 6 & 0.017 & 12.0 & 0.8 & 10 & 0.1690 & 0.66 \\
\hline Case 2.13 & 0.5 & 8 & 6 & 0.017 & 20.3 & 0.8 & 10 & 0.1699 & 0.65 \\
\hline Case 3.1 & 1 & 4 & 4 & 0.050 & 12.1 & 0.8 & 10 & 0.1981 & 0.67 \\
\hline Case 3.2 & 1 & 4 & 4 & 0.050 & 17.4 & 0.8 & 10 & 0.1991 & 0.65 \\
\hline Case 3.3 & 1 & 4 & 4 & 0.050 & 20.0 & 0.8 & 10 & 0.1989 & 0.60 \\
\hline Case 3.4 & 1 & 6 & 4 & 0.033 & 12.6 & 0.8 & 10 & 0.2020 & 0.5 \\
\hline Case 3.5 & 1 & 6 & 4 & 0.033 & 17.0 & 0.8 & 10 & 0.2024 & 0.55 \\
\hline Case 3.6 & 1 & 6 & 4 & 0.033 & 20.3 & 0.8 & 10 & 0.2029 & 0.54 \\
\hline Case 3.7 & 1 & 4 & 6 & 0.033 & 12.0 & 0.8 & 10 & 0.2041 & 0.51 \\
\hline Case 3.8 & 1 & 4 & 6 & 0.033 & 16.9 & 0.8 & 10 & 0.2049 & 0.50 \\
\hline Case 3.9 & 1 & 4 & 6 & 0.033 & 20.0 & 0.8 & 10 & 0.2050 & 0.47 \\
\hline Case 3.10 & 1 & 6 & 6 & 0.022 & 12.1 & 0.8 & 10 & 0.2102 & 0.30 \\
\hline Case 3.11 & 1 & 6 & 6 & 0.022 & 19.8 & 0.8 & 10 & 0.2120 & 0.35 \\
\hline Case 3.12 & 1 & 8 & 6 & 0.017 & 12.0 & 0.8 & 10 & 0.2199 & 0.30 \\
\hline Case 3.13 & 1 & 8 & 6 & 0.017 & 20.1 & 0.8 & 10 & 0.2212 & 0.28 \\
\hline
\end{tabular}

\subsection{Measurement of the spatially averaged velocity}

The vegetation elements were arranged in a regular pattern. Being similar to the definition of vegetation density used in previous studies (Ghisalberti \& Nepf 2002, Zong \& Nepf 2009, Huai et al. 2015), in this study, the vegetation density $\alpha$ was defined as follows:

$$
\alpha=\sum_{i}^{n_{o}} A_{i} / S / H
$$

where $A_{i}$ is the frontal area of a vegetation element, $S$ is the referred bed area, and $n_{o}$ is the number of elements occupied in $S$ (Fig. 1). Three flow depths and five levels of vegetation densities were tested in the experiments. The vertically averaged velocity, which is used to describe the incipient motion velocity without vegetation, is not appropriate to describe the incipient motion of sediment with vegetation due to the non-uniform spatial distribution of velocity within vegetation zone. So a new experimental statistics method is developed to describe the incipient motion of sediment with vegetation, which is that the spatially averaged velocity is used as a substitute for the vertically averaged velocity. Locations are chosen in the unit bed to measure the profiles of velocity along the z-axis to obtain the vertically averaged velocity at each location $i$, where the distance between adjacent locations is $1 \mathrm{~cm}$, as shown in Fig. 1. The spatially averaged velocity under the interface between water and vegetation $(z=H)$ is obtained using Eq. (7). 


\section{CRITERION OF THE SEDIMENT INCIPIENT MOTION WITH SUBMERGED RIGID VEGETATION}

The motion of sediment with submerged rigid vegetation has some unique characteristics compared to the motion of sediment without vegetation. Based on observations during the experiments, the status of the sediment in the bed can be divided into three processes.

In the first process, the bed sediment remains static at a low flow velocity. In Fig. 5(a), there is no sediment motion anywhere over the bed.

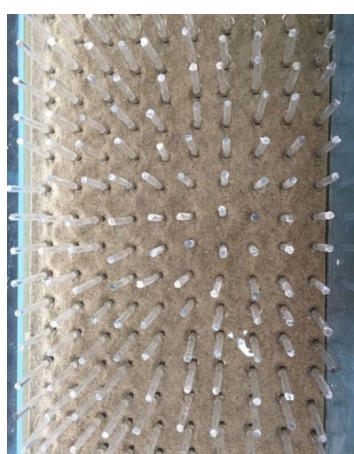

(a) Static

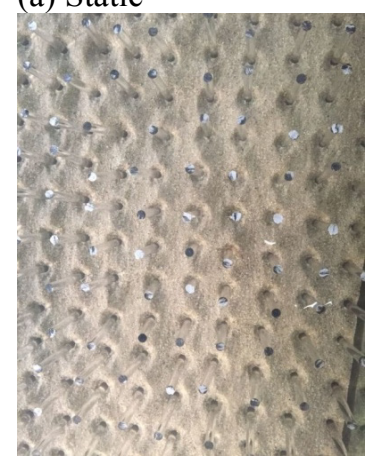

(c) Entirely motion

Figure 5. Three processes of the sediment incipient motion

Fig. 5(b) shows the second process. Sediment around some rigid vegetation elements starts to move after the water velocity exceeds a certain threshold, and scour holes gradually develop around these rigid vegetation elements due to the flow scouring. As the water velocity increasing, these scour holes gradually become deeper and larger. However, the sediment motion around vegetation elements always ceases once these scour holes reach an equilibrium state. Besides, some sediment ridges downstream of scour holes are also produced due to the gravity of the sediment. The flow in the vegetation zone is not uniform any more due to the existence of vegetation, therefore, the equilibrium bedform is not flat but rather contains scour holes and sediment ridges around vegetation elements. Therefore, the local sediment moving in this process is considered only a local adjustment of the sediment bed, rather than the initiation of overall sediment motion in the flow around the vegetation.
Fig. 5(c) shows the third process. When the water velocity increases to a certain value, a noticeable sediment transport out of all the scour holes around rigid vegetation elements and outside the vegetation zone is observed. The spatially averaged velocity at this threshold state is considered as the incipient motion velocity for sediment in the presence of submerged rigid vegetation. Zhang (1998) suggested that both sediment transport and local sediment movement could describe the incipient motion condition in flows without vegetation. However, in this study, the motion of local sediment is clearly observed to occur prior to the existence of sustaining sediment yield due to the effect of the vegetation elements on the flow. Therefore, the third process is defined as a criterion for the incipient motion condition of sediment in channel with submerged rigid vegetation.

\section{RESULTS AND DISCUSSION}

Previous researchers (Zhang 1998, Kramer 1935) suggested the criterion for incipient motion of sediment without vegetation, that there were a few countable sediment particles on the bed beginning to move. The experimental data obtained from the experiments without vegetation agreed well with the Eq. 10 by Zhang (1998), as shown in Fig. 6.

$$
U_{c}=\left(\frac{h}{d}\right)^{0.14}\left[17.6 \frac{\rho_{s}-\rho}{\rho} d+0.000000605 \frac{10+h}{d^{0.72}}\right]^{1 / 2}
$$

where the unit of the flow depth $h$ and the diameter of the sediment $d$ are meter.

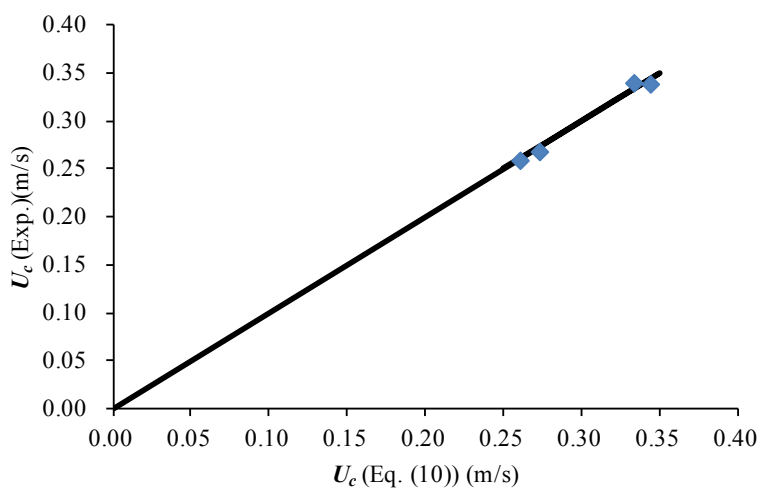

Figure 6. Comparison of the sediment incipient velocity without vegetation between calculated $U_{c}$ (Eq. (10) and experimental $U_{c}$

As mentioned before, the incipient motion of sediment with vegetation is defined by the spatially averaged velocity for sediment incipient motion $U_{p c}$ under the interface between vegetation and water $(z$ $=H$ ) at the third process (Fig. 5(c)). Fig. 7 shows the relationship between the observed $U_{p c}$ and the vegetation density $\alpha$. From Fig. 7, this relationship is highly sensitive and the $U_{p c}$ gradually decreases with increasing the vegetation density $\alpha$. 


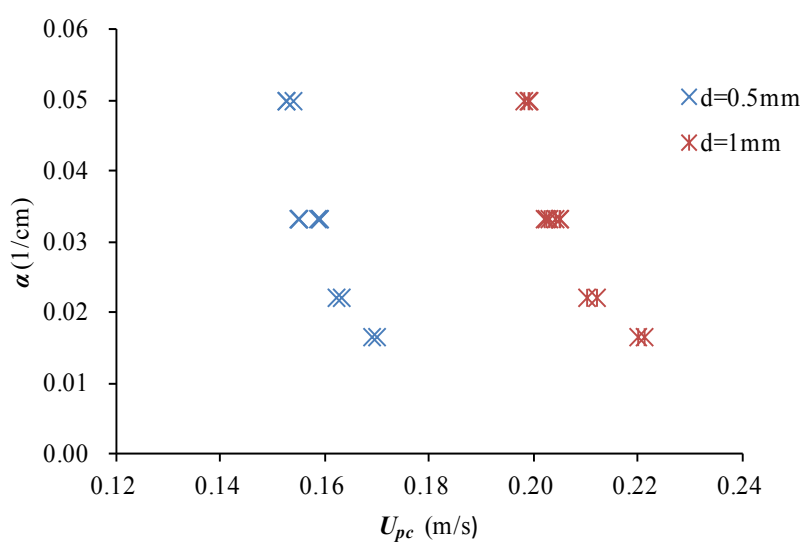

Fig. 7 The change of the spatially averaged velocity for sediment incipient motion $U_{p c}$ over vegetation density $\alpha$

Substituting experimental data into Eq. (8), a new equation is obtained as follows:

$U_{p c}=0.463\left(\frac{h}{d}\right)^{0.14}\left[17.6 \frac{\rho_{s}-\rho}{\rho} d\right.$

$\left.+0.000000605 \frac{10+h}{d^{0.72}}\right]^{1 / 2}\left[\left(\frac{D H}{h d}\right)^{0.04}\left(\frac{1 / L_{v}-\alpha}{\alpha}\right)^{0.29}\right]^{0.53}$

Fig. 8 shows the comparison of the experimental $U_{p c}$ with the calculated $U_{p c}$ by Eq. (11).

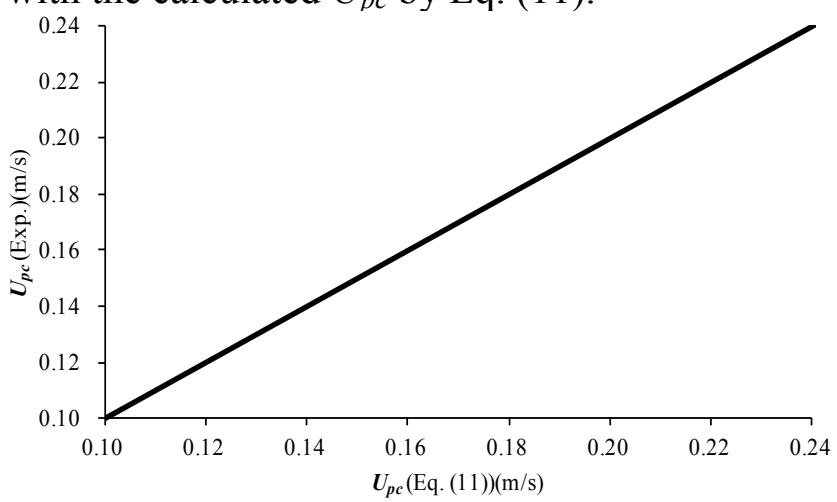

Figure 8. Comparison of the sediment incipient velocity with vegetation between calculated $U_{p c}$ (Eq. (11)) and experimental $U_{p c}$

In the second process as described above, numerous scour holes around the vegetation elements are observed in the vegetation zone before incipient motion of the sediment, and the bed-form has been deformed. Since the depths of the scour holes around different vegetation elements have slightly difference, so the average depth of the scour holes $d_{h a}$ after scour reaching equilibrium is used to investigate the scouring characteristic in the open channel with sediment-bed.

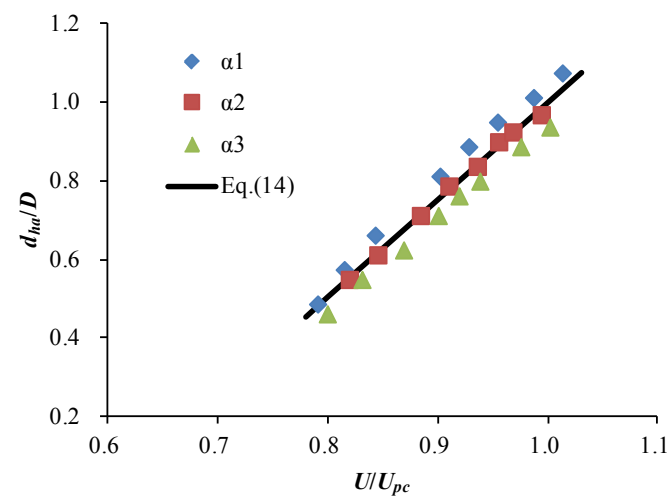

Fig. 9 Variation of non-dimensional averaged depth scales of scour hole around vegetation elements over the spatially averaged velocity ( $\left.\alpha_{1}=\alpha_{\text {Case 2.1 }}, \alpha_{2}=\alpha_{\text {Case 2.4 }}, \alpha_{3}=\alpha_{\text {Case 2.7 }}\right)$

Variation of the various non-dimensional averaged-depth scales of scour hole around vegetation elements are shown in Fig. 9, wherein the corresponding scour depth $d_{h a} / D$ is plotted against the spatially averaged velocity $U / U_{p c}$. From Fig. 9, the average depth of the scour holes $d_{h a}$ increases with the vegetation density $\alpha$ increasing for a certain spatially averaged velocity $U$ due to the strong turbulent structures caused by the vegetation elements; And for a certain density of vegetation $\alpha$, the average depth of the scour holes $d_{h a}$ vary linearly with the spatially averaged velocity $U$. A linear fit to the data yields:

$d_{h a} / D=2.4738\left(U / U_{p c}\right)-1.4743$

Substituting $d_{h a} / D=0$ into Eq. (12), a value of $U / U_{p c}$ $=0.60$ is obtained for the experimental data. That is to say, the scour around the vegetation element firstly occurs at $U / U_{p c}=0.60$. This results support the observations of Chiew (1995) on the relationship between the flow velocity and the occurrence of scour holes. However, Chiew (1995) used a single cylinder pier to conduct experiments and shown that the $U / U_{p c}=0.5$ which is less than that in our paper. This is because the incipient velocity of sediment for the case of an array of rigid elements is smaller than that with no vegetation.

\section{CONCLUSIONS}

The incipient motion of sediment in the open channel with the submerged rigid vegetation elements was investigated by experimental observations. Because the motion of local sediments occurred prior to yielding to sediment transport, the incipient motion of sediment was divided into three processes, the static, the partially motion, and the entirely motion, and we adopted the third process as the criterion for incipient motion of sediment. Based on the experimental results, the semi-empirical equation Eq. (11) was derived to describe the sediment incipient velocity in the presence of submerged vegetation, which is observed to be smaller than that without vegetation. 
The scour around the vegetation element firstly occurred at $U / U_{p c}=0.60$ which is larger than that at which scour occurs for a single pier. And the average depths of the scour holes around the vegetation elements have a linear relationship with the spatial averaged velocity under the water-vegetation interface for a certain vegetation density.

\section{ACKNOWLEDGMENTS}

This work was supported in part by grants from the Natural Science Foundation of China (Nos. 51409165, 51379128), the Jiangsu Province Postdoctoral Science Foundation funded project (No. 1402070B), the National Water Pollution Control and Management of Science and Technology Major Projects (No. 2012ZX07506-003-04), the Special Research Funds for Public Welfare of the State Ministry of Water Resources (No. 201301041, 201401063) and the Nanjing Hydraulic Research Institute Postdoctoral Science Foundation funded project (No. BH11402, Y114007). The authors thank Ph.D. candidate Wang Fangfang and M.Sc. Yang Qianqian for their help in the vegetation flow scour experiment. The authors would like to thank the anonymous reviewers for providing numerous constructive suggestions.

\section{REFERENCES}

Chiew Y.M. 1995. Mechanics of riprap failure at bridge piers. Journal of Hydraulic Engineering 121: 635-643.

Choi S.U. \& Kang H. 2004. Reynolds stress modeling of vegetated open-channel flows. J Hydraul Res 42(1): 3-11.

Dunn C. Lopez F. \& Garcia M.H. 1996. Mean flow and turbulence in a laboratory channel with simulated vegetation. In: Hydraulic engineering series, vol. 51, UILUENG- 96-2009. UIUC, Urbana, USA.

Elliott A. 2000. Settling of fine sediment in a channel with emergent vegetation. Journal of Hydraulic Engineering 126,570 .

Follett E. \& Nepf H. 2012. Sediment patterns near a model patch of reedy emergent vegetation. Geomorphology 179: 141-151.

Ghisalberti M. \& Nepf H.M. 2002. Mixing layers and coherent structures in vegetated aquatic flows. $J$ Geophys Res 107(C2):3,1-3,11.

Ghisalberti M. \& Nepf H.M. 2004. The limited growth of vegetated shear-layers. Water Resour Res 40(W07502):1-12.

Huai W. Xue W. \& Qian Z. 2015. Large-eddy simulation of turbulent rectangular open-channel flow with an emergent rigid vegetation patch. Advances in Water Resources 80: $30-42$.

Keshavarzi A. Melville B. \& Ball J. 2014. Three-dimensional analysis of coherent turbulent flow structure around a single circular bridge pier. Environmental Fluid Mechanics 14(4): 821-847.

Kirkil G. Constantinescu S.G. \& Ettema R. 2008. Coherent structures in the flow field around a circular cylinder with scour hole. Journal of Hydraulic Engineering 134(5): 572587.
Kothyari U.C. Hashimoto H. \& Hayashi K. 2009. Effect of tall vegetation on sediment transport by channel flows. Journal of Hydraulic Research 47: 700-710.

Kramer H. 1936. Sand mixtures and sand movement in fluvial model. Transactions of the American Society of Civil Engineers 100(1): 798-838.

Lopez F. \& Garcia M. 1998. Open-channel flow through simulated vegetation: suspended sediment transport modeling. Water Resour Res 34(9): 2341-52.

Neary V.S. Constantinescu S.G. Bennett S.J. \& Diplas P. 2011. Effects of vegetation on turbulence, sediment transport, and stream morphology. Journal of Hydraulic Engineering 138(9): 765-776.

Nepf H.M. \& Vivoni E.R. 2000. Flow structure in depthlimited, vegetated flow. $J$ Geophys Res 105(C12): 28457557.

Shields A. 1936. Anwedung der aehnlichkeitmechanik und der turbulenzforschung auf die geschiebewegung, Mitt, Versuchsanst. Wasserbau schiffbau 26.

Specht F.J. 2002. Einfluss von Gerinnebreite und Uferbewuchs auf die hydraulishch sedimentologischen verha“ltnisse naturnaher Fliessgewa“"sser. Technische Universita"t, Braunschweig, Germany.

Tal M. \& Paola C. 2010. Effects of vegetationon channel morphodynamics: results and insights from laboratory experiments. Earth Surf Process L and forms 35(9): 1014-1028.

Tang C.B. 1963.The law of sediment incipience. J Hydraulic Engineering 2: 1-12.

Watanabe K. Nagy H. \& Noguchi H. 2002. Flow Structure and Bed-load Transport in Vegetation Flow 214-218.

White B.L. \& Nepf H.M. 2008. A vortex-based model of velocity and shear stress in a partially vegetated shallow channel. Water Resour Res 44: W01412.

Yan J. Xiao Y. Liu T. \& Liu C. 2006. Velocity Measurement of Open Channel Flow with Submerged Rigid Vegetation Using PIV, 15th APD-IAHR, India. 163-168.

Zhang R. \& Xie J. 1998. River sediment dynamics. China WaterPower Press.

Zong L. \& Nepf H. 2010. Flow and deposition in and around a finite patch of vegetation. Geomorphology 116: 363-72.

Zong L. \& Nepf H. 2011. Spatial distribution of deposition with in a patch of vegetation. Water Resour Res 47: W03516. 